\title{
Making sense of the constellations of (im)mobility of Bangladeshi migrants in Greece
}

\author{
Loukia-Maria Fratsea $^{1}$ and Apostolos G. Papadopoulos ${ }^{2}$
}

Abstract

Over the last three decades of the $20^{\text {th }}$ century, Greece was transformed from an emigration into an immigration country and, more recently, into a country combining emigration and immigration. Initially, immigration from the 'Balkans' was at the heart of the country's migration debates. However, since the early 2000s, migration inflows have been highly differentiated, and the numbers have increased for both Asian and African migrants. During the era of austerity, Bangladeshis have followed diverse employment pathways and spatial trajectories. Their so-called constellations of (im)mobility' cover an array of socio-spatial mobility patterns, ranging from being entrapped in precarious jobs to gaining access to/ striving towards more prestigious occupational positions (self-employed occupations). Drawing on recent empirical research, this paper seeks to explore the multidimensional precarity of Bangladeshi migrants living in Greek urban and rural areas. Given the dynamic interplay between macro- and micro-level processes, it also discusses aspects of agency along with practices and strategies for improving the well-being of Bangladeshi migrants in the host society.

Keywords: Mobility; Bangladeshi migrants; Greece; precarity; agency

\section{Introduction}

Over the last three decades of the $20^{\text {th }}$ century, Greece was transformed from an emigration into an immigration country and, more recently, into a country combining emigration and immigration flows. Greece's transformation into a migrant receiving country has been analyzed in view of the "Southern European migration model", which looks at the evolution of migration towards Greece, Italy, Spain and Portugal as a special case which relates, on the one hand, to the differentiation and globalization of migration flows and, on the other, to the way in which migrants in Southern European countries are embedded in the specific model of South European post-industrial society (King 2000: 3).

Geography plays a significant role for immigration in Greece. During the 1990s, most migrants originated from the neighbouring countries in the Balkans (Cavounidis 2004; Papadopoulos 2011) with smaller numbers of economic migrants and asylum seekers originating from Asia and Africa. Thus, since the start, immigration from the 'Balkans', and 'Albanian' migration, in particular, has been at the heart of the country's migration debates, since Albanians make up approximately 60 percent of the migrant population. Yet, since the

\footnotetext{
${ }^{1}$ Loukia-Maria Fratsea, Researcher, Department of Geography, Harokopio University, Athens, Greece.

Email: fratsea@hua.gr.

2 Apostolos G. Papadopoulos, Director of the Institute of Social Research, National Centre for Social Research (EKKE) and Professor of Rural Sociology and Geography, Department of Geography, Harokopio University, Athens, Greece.

Email: apospapa@hua.gr.
} 
early 2000s, migration flows towards Greece have been highly differentiated. Geographical proximity to Greece would become steadily less important as a factor in migration than its geographic accessibility (Papadopoulos 2011; Papadopoulos et al. 2013). In this context, Asians together with African migrants increased in numbers. According to the latest population census, Greece's migrant population numbered 912,000 people, or 8.4 percent of the total population (Population Census 2011). Among the largest national groups of migrants are Albanians (52.7 percent of migrants), Bulgarians (8.3 percent), Romanians (5.1 percent), Pakistanis (3.7 percent), Georgians (3 percent), Poles (1.6 percent), Indians (1.2 percent) and Bangladeshis (1.2 percent).

Despite the growing number of South Asian migrants and their long presence in the country, South Asian--and particularly Bangladeshi--migration in Greece is relatively neglected in the national research. The limited research focuses mainly on urban areas and considers the concentration and overall characteristics of Asian migration in Greece; when Bangladeshi migrants are researched at all, Greece is depicted primarily as transit country (Dimitriadi 2013). $\mathrm{By}$ and large, previous research overlooks the fact that there are a significant number of Bangladeshis living and working in the Greek countryside, and that they contribute significantly to agriculture and local economic development (Kasimis et al. 2015; Papadopoulos et al. 2018). What is more, the Bangladeshi community in Greece is a rather diverse group, in terms both of its socioeconomic characteristics and of its legal statuses, which brings to the fore various integration challenges and prospects.

The recent economic recession in Greece created a new setting for the employment and integration of migrants, while the implications of the recent pandemic are only now becoming clear. During the era of austerity, migrants were among the most vulnerable groups in the labour market. After the economic downturn in 2008, Greece's GDP shrank by 26 percent, while unemployment skyrocketed to 27.5 percent in 2013 (OECD 2016: 20); the risk of poverty and income inequality increased (Ketsetzopoulou 2017; Mitrakos 2018). Most Bangladeshis have an irregular or semi-irregular status, while the adverse socioeconomic context of the downturn affected their employment opportunities, their social and spatial mobility pathways, and/or their migration aspirations and plans. We can see the precarious status of Bangladeshi migrants in Greek society as a double-edged sword: while, for some, it can serve as a springboard for elaborating new social and spatial mobility ambitions and practices, for others it acts as a vicious circle which traps them at the lower end of the social and occupational spectrum with limited opportunities for escaping that loop.

This paper focuses on the diverse (im)mobilities and multidimensional precarity of Bangladeshi migrants working and living in urban and rural areas in Greece. Our methodological approach in this paper synthesizes analysis of the statistical data available on Bangladeshi migrants in Greece, fieldwork research and ethnographic observations, the qualitative interviewing and life histories of Bangladeshi migrants, and interviews with key informants. We generally conducted interviews in Greek and/or English, and though willing Bangladeshi nationals would occasionally act as informal translators for us to and from the Bengali. Pseudonyms have been used for the interviewees, to safeguard their anonymity.

After a short theoretical discussion on (im)mobility, precarity and migrant agency, the paper presents the characteristics of Bangladeshi migration in Greece and analyses aspects of the diverse social and spatial pathways of Bangladeshis in the country. In the concluding section, the paper argues that there is a dynamic interplay between macro- and micro-level processes 
which shapes the (im)mobility pathways of Bangladeshi migrants. Social and spatial mobility or immobility is perceived differently depending both on the immigrants' aspirations and socioeconomic status and on the changing context of the receiving society.

\section{Migrants' (im)mobilities and the multiple dimensions of precarity}

The concept of mobility is at the core of contemporary debates in migration studies. The concept "encompasses both the large-scale movements of people, objects, capital and information across the world, as well as the more local processes of daily transportation, movement through public space and the travel of material things within everyday life" (Hannam et al. 2006: 1). It is argued that the 'new mobilities' paradigm challenges the sedentary bias of social science research (Sheller and Urry 2006).

Thus, a mobilities approach in migration studies goes beyond the traditional interpretation of movement(s) as linear trajectories to encompass movement and fixity, movers and nonmovers, their interconnections, places and power relations on various scales (Cresswell 2001; Sheller and Urry 2006; Cohen and Sirkeci 2011; Priori 2017) creating a complex assemblage of movement, social imaginaries and experiences (Salazar 2011; Glick Schiller and Salazar 2013). Nevertheless, mobility and immobility are not merely contrasted concepts or opposite sides of the same coin. Rather, there are different forms and facets of mobility and stasis (stoppage) whose boundaries are sometimes blurred, and which come into view when the light falls on them at a particular angle. In other words, examining (im)mobility processes also places the emphasis on the individuals who experience, interpret and assess different pathways. In this context, an individual may experience both mobility phases and immobility in a life cycle (van Hear 2014; Priori 2017); what could seem at first to outsiders to be 'staying still' may include various aspects of mobility (Cresswell and Merriman 2011), from the mover's point of view. Following such lines, expectations, migration aspirations and migration plans and imaginaries can be considered mobility-in-the-making, as these can boost the conviction required to embark on a migratory journey triggered by the assumption that a better livelihood will be made feasible by moving somewhere else.

Nevertheless, the degree of freedom required to move to some other place cannot be taken for granted. Carling (2002) argues, quoting some of the most influential books, that we live in "Worlds in Motion" and in an "Age of Migration", but also in the "Age of Involuntary Immobility", as the Covid-19 crisis revealed. Given the structural -perceived or actual-, limitations on mobility, in his analytical framework, he associates the aspiration to migrate with the capability to do so, for movers and non-movers. Elaborating on this model, de Haas et al. (2020) argue that aspirations, choice and migrant agency are important components of (im)mobility processes. Pursuing such arguments, as we will see in the case of Bangladeshi migrants in Greece, immobility is not always related to limited migrant agency, but can actually become a manifestation of agency. Similarly, mobility can be seen as a strategy or practice got escaping a precarious position in the labour market, while immobility can be seen as an entrapment in precarity.

The precarious position of migrant workers has been the subject of many academic and policy debates. Standing's contribution to the discussion on precarity and the 'precariat' (Standing 2011) remains a useful starting point (Shukaitis 2013; Paret 2016), despite the severe criticism that it received (Breman 2013; Munck 2013). We can see precarity as a multidimensional concept because it consists of various meanings and roles (Shukaitis 2013: 657), while it also 
takes various forms that cannot be easily separated (Paret and Gleeson 2016). Following Papadopoulos et al. (2018), we identify four types of precarity which are important for examining Bangladeshi migration processes in Greece. First, migrants' precarious legal status. Legal status determines access to an entire range of social rights and social services in the receiving society, with different legal or semi-legal statuses linked to different rights, obligations and socio-spatial trajectories. Second, labour precarity. This refers to precarious work, which encompasses work for which social security payments are not made as well as unpaid or under-paid work. Connected to this is workplace precarity, which relates to the spatial aspects of precarity which arise from the actual places of employment. For instance, the physical setting/ morphology of the workspace, the sanitary aspects of work, and the relations between migrant labourers and their employers are major elements in the everyday experience of precarity. Fourthly, life precarity connects to existential precarity, and also relates to the migrant's incorporation into local society, their standard of living (e.g. access to clothing, education and security), and their 'sense of belonging' in the local community / receiving society.

\section{Bangladeshi migration to Greece}

South Asian migration to Greece dates to the 1970s and was connected to bilateral agreements signed by Pakistan and Greece enabling the temporary employment of Pakistani workers. Indeed, in the 1981 and 1991 population censuses, the number of South Asian migrants mainly migrants of Pakistani, Indian and Irani origin - was 2,404 and 4,481 people, respectively. In contrast, Bangladeshi migration to Greece is a more recent phenomenon which should be viewed within the wider globalisation of flows and the role of Turkey as an emerging 'migration hub' for the Middle East (Elitok and Straubhaar 2011) and Africa (Papadopoulos and Fratsea 2015), but also in terms of the evolution of migration and asylum policy in the European Union and Greece. Furthermore, as in the case of Italy (see Knights and King 1998), there are no prior colonial, religious, economic and linguistic ties between Bangladesh and Greece, which could partly explain the development of the Bangladeshi community in Greece.

The first reference we found to Bangladeshi migration in the published official records dates from 1998, when Greece launched its first regularization programme. At that time, 3,024 Bangladeshi migrants applied for regularization (Cavounidis 2002: 50). A few years later, in the 2001 Population Census, the number of Bangladeshi migrants in Greece had risen to 4,960 people, while by 2011 this figure had doubled to 11,076 or 16.8 percent of the South Asian migrants in Greece. Currently, Bangladeshi migrants in Greece represent the second most numerous South Asian nationality after the Pakistani.

Based on the analysis of the available statistical information and empirical material, there are several issues concerning the characteristics of Bangladeshi migration in Greece:

First, Asian migration flows towards Greece are increasing in volume. In fact, considering the data relating to the apprehension of irregular migrants in Greece from 2010 onwards (Figure 1), it is evident that Asian nationalities corresponds to a significant proportion of total apprehensions. These figures peaked in 2015, when Greece witnessed unprecedented numbers of people crossing its borders. Although this movement was triggered by the conflicts and crisis in Syria; the number of South Asian migrants amounted to 269,104 people, representing an astonishing increase of 1,378 percent, comparing to the previous period. In 
fact, Bangladeshi inflows in 2015 almost quadrupled in comparison to previous years, reaching 4,511 people; in 2018, the number dropped to 2,054.

Second, despite their length of residence in the country, an important percentage of Bangladeshi migrants in Greece remain irregular or semi-irregular in terms of their legal status. We should see this situation in the context of migration policy in Greece. Indeed, from 1997 to 2007, four legalization programs were implemented in the country. A good number of migrants - the majority of Albanian origin - who were already living in Greece acquired legal status. However, in practice, the more recent flows of migration remained excluded from obtaining legal status. Thus, looking at the number of residence permits issued over the last decade, we see that Bangladeshi migrants still hold a small percentage of the total residence permits in the country, though they account for a significant share (20 percent) among South Asian migrants (Figure 2). More to the point, the number of Bangladeshi migrants who hold a valid residence permit increased from 5,238 in 2008 to 9,207 in 2018. Despite the conceptual and methodological issues besetting the calculation of the actual number of irregular migrants (Koser 2010), the spokesperson for the Bangladeshi association in Greece (Nazir, 48 years old) estimates that half of the Bangladeshi community still remain in an irregular or semiregular status. It should also be noted that between 2009 and 2017, a total of 110 Bangladeshis acquired Greek nationality. This figure remains low compared to the total number of acquisitions. For instance, Greece granted citizenship to 34,305 people in 2017 (Eurostat 2020b).

Figure 1. Apprehensions of irregular migrants by geographical area, 2010-2018

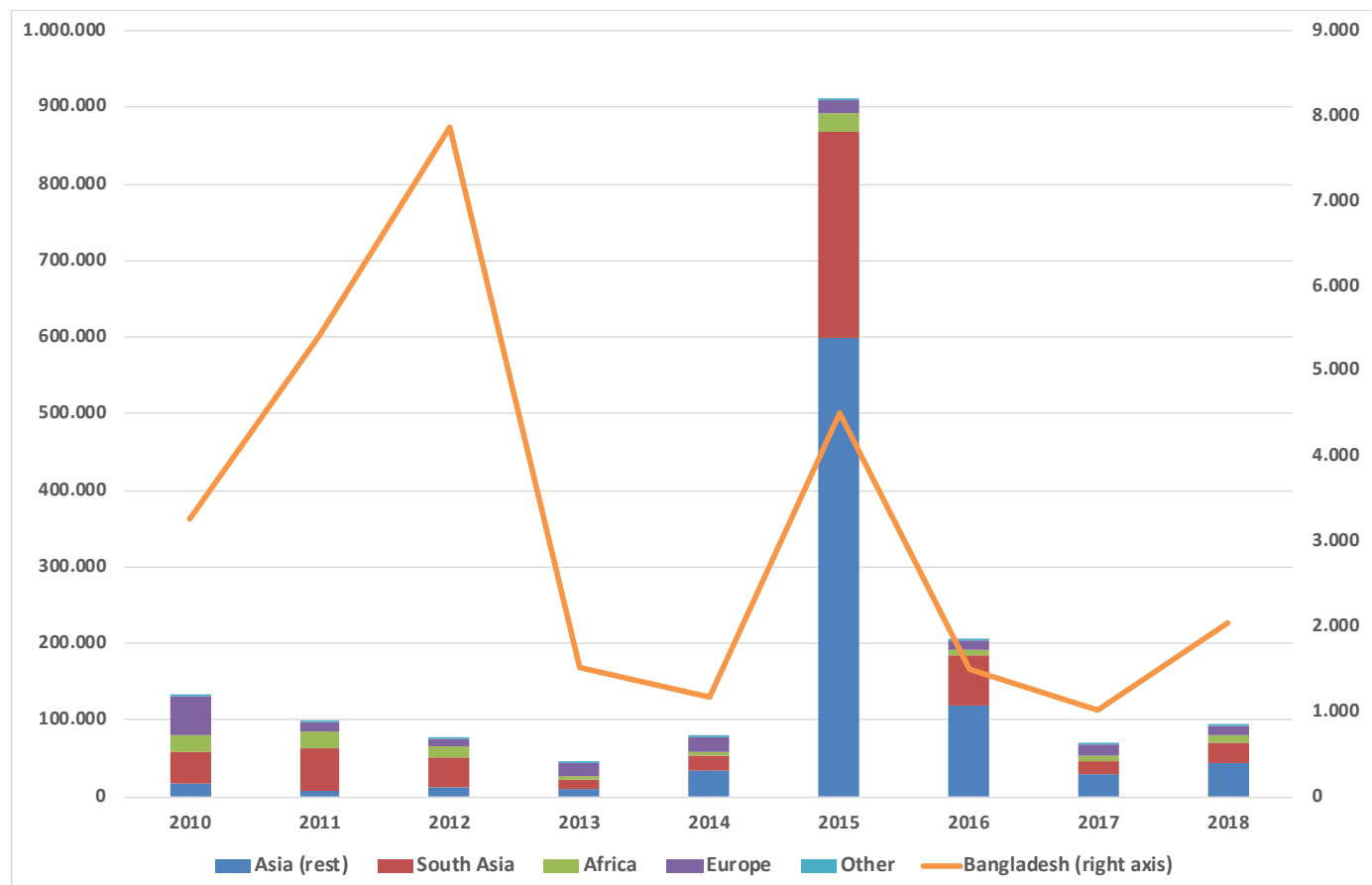

Source: Hellenic Ministry of Citizen Protection, Hellenic Police 2010-2020. Data elaborated by the authors. 
Figure 2. Valid residence permits held by South Asian migrants, 2008-2018

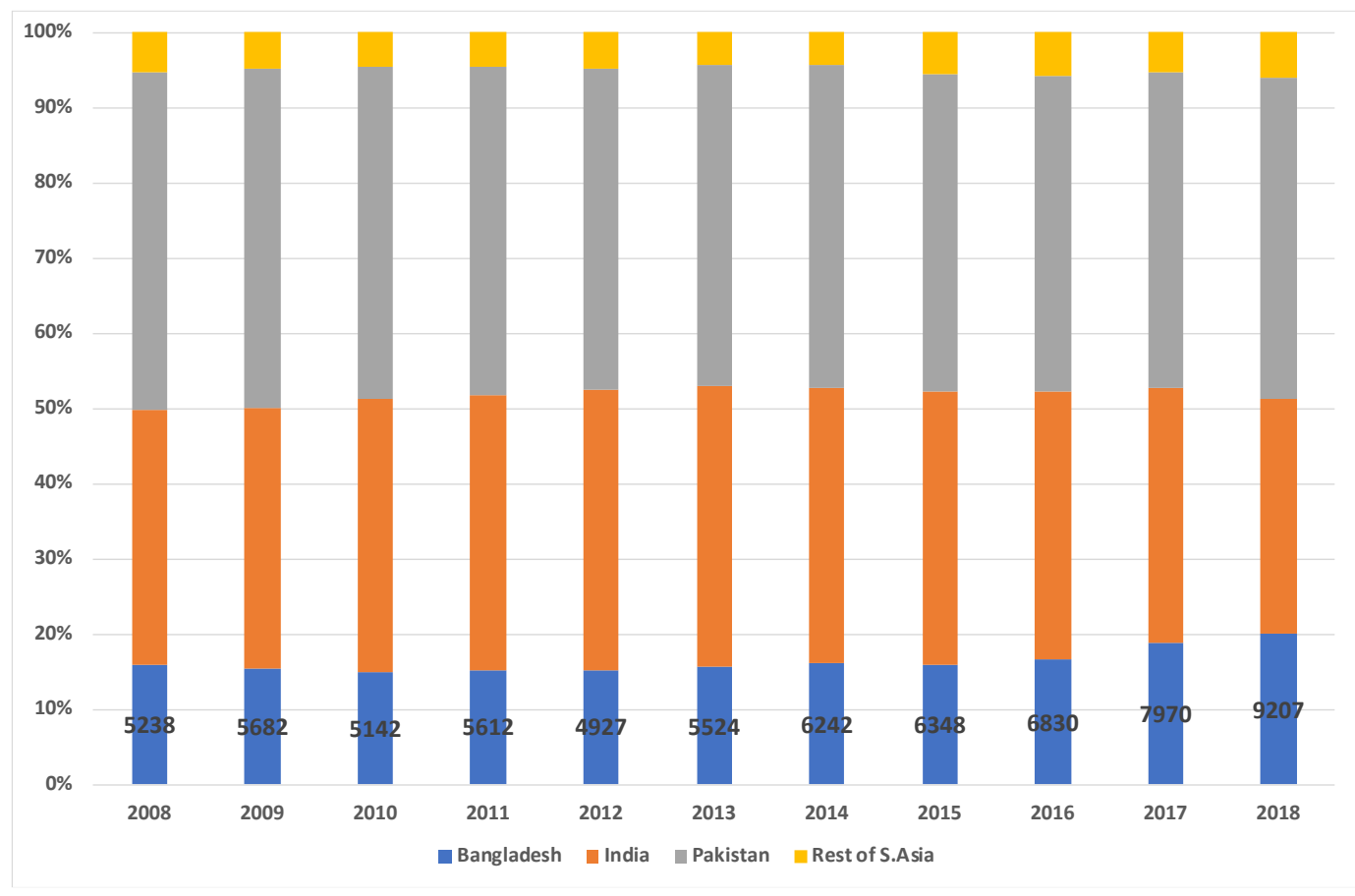

Source: Eurostat 2020a.

Third, the distribution of gender and age groups suggests that Bangladeshi migrants in Greece are a young population of working age, with the majority ( 42.6 percent) being between 25 and 34 years old. Additionally, Bangladeshi migration in Greece is male dominated. Based on the Population Census data for 2011, the proportion of females as a share of total Bangladeshi migrants is just 7 percent. This is also evident when we examine the recent residence permit data from the Ministry of Migration and Asylum (data from December 2019). More particularly, females account for over 9 percent of a total of 9,183 residence permits issued to Bangladeshi migrants, with the vast majority ( 79.3 percent) of such permits issued in view of family reunification. Regarding marital status, 42.7 percent of Bangladeshi migrants are married, although their family (spouse and children) usually remains in their country of origin (ELSTAT Population Census 2011).

In terms of educational attainment, only 4.5 percent of Bangladeshi migrants have tertiary education, while over one third have secondary and post-secondary education. Although the number of Bangladeshi women is small, their educational attainment is on average higher than their male counterparts. For example, 4.1 percent of Bangladeshi men have tertiary education compared to 8.2 percent of women (ELSTAT Population Census 2011). Nevertheless, it is worth noting that despite their educational profile, Greek language proficiency is on average poor, an issue that hinders occupational mobility and raises issues of discrimination and obstacles to participating in the formal labour market.

Participation in the labour market is a key element in the overall process of integration into the host society. Based on Population Census data, the vast majority of Bangladeshi migrants 
are employed (73.1 percent), although unemployment is high. Entrepreneurship is relatively high, with 15 percent of the Bangladeshi labour force are employers or self-employed (running shops, Asian restaurants, convenience stores, etc.), while 71 percent are employees or paid daily. The sectoral distribution of Bangladeshi migrant workers shows that the majority (45.2 percent) are employed in the service sector (catering services, tourism, trade), a quarter of the workforce is employed in the secondary sector (mainly in garment manufacturing and food processing), while a significant percentage (19.2 percent) are employed in agriculture. Additionally, when considering the categorization of the Bangladeshi labour force into professional groups, it is evident that the great majority (64 percent) are employed in lowstatus professions, while just short of a quarter are employed in middle-status jobs. In other words, most of the Bangladeshi population is concentrated in low-status occupations with limited opportunities for upward social mobility.

The analysis of the spatial distribution of Bangladeshis in Greece highlights interesting migration and mobility patterns. More particularly, based on the latest census data, it seems that Bangladeshi migrants are concentrated in two parts of the country: the Attica Region, where more than 78 percent live, and the Region of Western Greece, which is home to 15.8 percent. If we take this analysis one step further, it becomes apparent that the majority of Bangladeshi in Greece are concentrated in the Centre of Athens and the Regional Unit of Ilia. Their spatial segregation in Athens should be seen in conjunction with the wider socioeconomic transformations that have taken place, the social mobility of residents, the evolution of the migratory phenomenon in the country, and the labour market opportunities that the capital city can offer the migrant population (see, for example, Arapoglou and Maloutas, 2011; Kandylis and Maloutas 2012). The Municipal Unit of Ilia, which is characterised as a predominantly rural area, presents many employment opportunities in the intensive agricultural/ horticultural sector, while migrant employment played a crucial role in the expansion of strawberry cultivation in the area (Papadopoulos and Fratsea 2017).

To sum up, Bangladeshi migration to Greece is a relatively recent phenomenon. The Bangladeshi community in Greece is rather diverse, in terms of both socioeconomic characteristics and legal status. Half to more than half of the Bangladeshi community in Greece live on the fringes of regularity, which intensifies their sense of life precarity. All in all, precarity has evolved into a mode of living that supresses their lives but also operates as leverage, mobilizing them against external constraints and limitations.

\section{Constellations of Bangladeshi (im)mobility}

An examination of the evolution and the geography of Bangladeshi migration in Greece, reveals different (im)mobility patterns connected to the multidimensional precarity of many migrants in Greece. In addition, the recent economic recession severely affected the precarious position of Bangladeshi migrants in the Greek labour market. During the interviews, it was repeatedly mentioned that the economic crisis reinforced practices of underpayment or non-payment of wages, physical and verbal abuse in the workplace, and violence and xenophobia and racist attacks, presumably committed by Golden Dawn. According to our interviewees, these incidents were both more numerous and more severe in the case of Bangladeshi migrants with an irregular or semi-regular status. The following paragraphs draw from the narratives of Bangladeshi migrants regarding their spatial and social mobility strategies and the way these are affected by the changing socioeconomic situation in 
Greece. Considering the dynamic interplay between macro- and micro-level processes, we can see the deteriorating working and living conditions as a double-edged sword; some see those conditions as a springboard for elaborating new social and spatial mobility strategies, while others are entrapped in a vicious circle which leads to the lower end of the social and occupational spectrum, with limited opportunities for social and/or spatial mobility.

Born in 1977 in a village near Chittagong, Nobel decided to move away from low-paid, odd jobs in the village and moved first to India and subsequently to Pakistan. After 12 years working in Pakistan, he resumed his mobility plans and moved to Iran and then Turkey. For him, Turkey was a transit country: he stayed just long enough to find a 'group' to help him cross the borders. He arrived in Greece in 2009 without papers or a residence permit and worked as a street vendor for four years. All this time, he considered his social position to have remained stable, without any advancement achieved, since he sensed he couldn't move to another country, or find a better job. He applied for asylum in 2013, received his 'pink card' and found a better job in a restaurant in Athens, working long hours (12-hour shift) for minimum wage plus social security. Despite his work precarity, he is pleased that he succeeded in securing a stable position plus legal status in Greece. By the time of our interview in 2017, he had been granted refugee status and emphatically claimed that "now I can go to Germany" (Nobel, mid-40s). In other words, his changing legal status altered the perceived and actual constraints on mobility and impacted on his aspirations for migrating onwards towards Europe (Della Puppa and Morad 2019). However, two years later in 2019, he is still working in Athens, though his plans to move West are still alive.

Other Bangladeshi migrants, after arriving in Greece and more particularly Athens, moved directly to rural areas. In the words of Atif: "When I arrived in Athens, I asked my compatriots where I could find work. They told me to go to Manolada. I came here and I stayed' (Atif, mid-30s). In fact, in recent years the Bangladeshi community has increased considerably in Western Greece, in the Peloponnese; Bangladeshi migrants, who had been living and working in different parts of Greece, and particularly Athens, saw new employment prospects in the intensive agricultural sector, using information about employment opportunities drawn from their social networks. Based on official figures, 1,747 Bangladeshis live in Western Greece, although informal estimates are higher. Seasonal mobility is a strategy for securing employment, especially in hard times. In fact, during the harvesting season, 1,000 to 1,500 Bangladeshi migrants move from Athens--and, to a lesser extent, from other parts of Greece-to Western Greece for the strawberry harvest. Recent estimates raise the number of workers from Bangladesh who have moved to the wider area of the Western Greece to around 4,000 (Manolada Watch, January 2019). Many Bangladeshi migrants live in very precarious conditions, usually without residence permits. They live in huts made of reeds and thick plastic in the fields where hygiene facilities are limited, paying a small 'rent' to the farmer. In terms of labour and residence they are 'entrapped', as they live and work in enclaves doing temporary, low-paid, heavy or dangerous work which is strongly related to the dominant capitalist production model based on labour control. Their life precarity, however, does not necessarily mean that they are passive victims; very often, they become active agents (Papadopoulos et al. 2018), illustrating the dynamics of the interplay between multidimensional precarity and migrant agency. In other words, the temporary precariousness may be a focus-oriented strategy aimed at improving the migrant's life course in the (imagined) future (Axelsson et al. 2017). Nevertheless, in the cases described, their integration into the 
host rural community may not be a primary aim; they may seek rather to be accepted as 'workers' and 'residents' in rural communities.

In 2013, Manolada in Western Greece, was in the spotlight: 150 Bangladeshi migrant workers, the majority without a work permit, went on strike three times to force their employers to pay them unpaid wages. When a workers' group demanded payment from their employers, one of the supervisors fired at the group, severely injuring thirty of them. This resulted in four suspects being arrested: a farm owner and three supervisors. On March 30, 2017, the European Court of Human Rights held that there had been a violation of Article $4 \$ 2$ of the Convention and that the applicants--forty-two Bangladeshi workers--had not received effective protection from the Greek State (ECHR 2017). Although Greece paid damages and granted residence permits to the Bangladeshi workers, the price that irregular Bangladeshi migrants had to pay was high. Shameem (40 years old) argues: "[Bangladeshis] may have gained legal residence permits after that (shootings), but the bullets are still in their bodies".

Bangladeshi migrants have taken entrepreneurial initiatives, opening new Asian restaurants and Asian mini-markets in both rural and urban areas. These businesses operate on co-ethnic and/or family-based recruitment, while their clientele are South Asians and Greeks. These places may also act as places where Bangladeshi migrants can bond, while in special cases important events take place (such as local elections). In contrast to most Bangladeshi migrants, the owners of these businesses live, or are planning to live, with their families in Greece, signalling a more permanent residence in the country.

Rali (male, mid-40s), arrived in Athens in 1994. At that time, the Bangladeshi community was very small, so he moved from rural area to rural area in search of a job in the fields. Following the regularization program, he moved to Athens where, after many years, he finally opened a mini-market in an upper medium-class neighbourhood in Athens. He argues that his sacrifices and determination to 'move on' has improved his status in Greece, as well as in his country of origin. Currently, he visits his family and children in Bangladesh annually, and he is waiting for his application for family reunification to be approved. His narrative sheds light on the social and spatial pathways that slip through the cracks of precarity. For him, hard work and establishing social networks with Greeks and Bangladeshis, were some of the ingredients of his upward mobility, despite the economic crisis in Greece. The present pandemic crisis has posed additional challenges as travel restrictions and border closures led to his being caught in Bangladesh during a visit to his family. He is still 'on waiting', involuntarily immobile, waiting to move back to Greece. At least he has something to look forward to, given than many of his compatriots were dismissed from their jobs in the Arab and Middle East countries due to the pandemic and were forced to return to Bangladesh (Sorkar 2020).

\section{Conclusions}

Bangladeshi migrants in Greece experience a mix of mobility and immobility. Periods of mobility are accompanied by periods of inertia and vice-versa. In other words, phases of voluntary and involuntary mobility and immobility (Carling 2002) can be detected during the life-course of Bangladeshi migrants. There are a myriad of dimensions which contribute to their precariousness; nonetheless, Bangladeshis retain their role as active agents, seeking to avail themselves of opportunities and overcome constraints stemming from their economic and political context in the receiving society, and following diverse employment and spatial pathways as a result. 
We have identified Bangladeshi migrant reactions to precarity with 'constellations of (im)mobility', to use Kesselring's (2006) term, which cover a wide spectrum of socio-spatial mobility patterns. Some migrants are trapped in precarious jobs, lacking access to basic social security, a regular time schedule, specific employment tasks or responsibilities attached to their position and, more generally, to prospects for improving their lives and position in the labour market. Others respond to the immobility that comes with precarious jobs by shifting to self-employment and/or entrepreneurship as a survival strategy (Valenzuela 2001), elaborating short- and medium-term plans which lead to social advancement. Which is to say that the Bangladeshi migrants come up with reactions to the challenges attached to precariousness and marginalisation. When they realise that they have reached an impasse and/or obtained a legal status (which provides them some shelter from precariousness), they opt for onward migration to other EU countries (Della Puppa and Morad 2019), while 'multiple migrations' (Ciobanu 2015) remain within the range of their migration plans.

The narratives of the Bangladeshi migrants provide evidence that migration trajectories are subjectively constructed by migrants as they follow paths of mobility or immobility constructed upon individual and/or groups assessments. The Bangladeshi migrants build these subjective constructions using existing and imaginary elements that enable them to aspire and, possibly, to overcome the constraints that are built into the migration system in Greece. The shifts from mobility to immobility and back again allow them to interpret and interact with the available options for their own well-being, while also bearing in mind possible improvements for their families. The lived experience of mobility and/or immobility provides the basis for elaborating more sophisticated migrant practices, while also informing migrants' mental constructs of a better destination. Our understanding of the ways in which Bangladeshi migrants construct their desired destinations leads us to conclude that they envision a wide variety of possible futures realised in spite of the limitations imposed by the economic crisis and the generalised enforcement of precariousness. In fact, the latter may provide them with the stepping stone they need to react, rework or even resist and, therefore, construct their own future either by pursuing their goals elsewhere or staying and fighting back to improve their well-being and quality of life.

\section{References}

Arapoglou, V. and Maloutas, T. (2011). Segregation, inequality and marginality in context: The case of Athens. The Greek Review of Social Research, 136(C’) 135-155.

Axelsson, L., Malmberg, B. and Zhang, Q. (2017). On waiting, work-time and imagined futures: Theorising temporal precariousness among Chinese chefs in Sweden's restaurant industry. Geoforum, 78, 169-178.

Breman, J. (2013). A bogus concept? New Left Review, 84, 130-138.

Carling, J. (2002). Migration in the age of involuntary immobility: Theoretical reflections and Cape Verdean experiences. Journal of Ethnic and Migration Studies, 28(1), 5-42.

Cavounidis, J. (2002). Migration in Southern Europe and the case of Greece. International Migration, 40(1), 4570.

Cavounidis, J. (2004). Migration to Greece from the Balkans. South Eastern Europe Journal of Economics, 2, 3559.

Ciobanu, R. O. (2015). Multiple Migration Flows of Romanians. Mobilities, 10(3), 466-485.

Cohen, J.H. and Sirkeci, I. (2011). Cultures of Migration: The Global Nature of Contemporary Mobility. Austin: The University of Texas Press.

Cresswell, T. (2001). The production of mobilities. New Formations, 43, 11-25.

Cresswell, T. and Merriman, P. (2011). Geographies of mobilities: Practices, spaces, subjects: Ashgate Publishing. 
De Haas, H., Castles, S. and Miller, M.J. (2020). The age of migration: International population movements in the modern world. UK: Red Globe Press [6th edition].

Della Puppa, F.D. and Morad, M. (2019). Migrants in Italy, Citizens in Europe? Trajectories, Experiences and Motivations of the Multiple Mobilities of Italian-Bangladeshis Relocating to London. Studi Emigrazione, 215, 473-491.

Dimitriadi, A. (2013). Transit and immigration to Greece. The case of Afghans, Pakistanis and Bangladeshis. Nissos, Athens (in Greek).

ECHR (2017). Migrants who were subjected to forced labour and human trafficking did not receive effective protection from the Greek State, Press Release. ECHR 112 (2017) 30.03.2017.

Elitok, S.P. and Straubhaar, T. (2011). Turkey as a Migration Hub in the Middle East. Insight Turkey, 13(2), $107-128$.

Eurostat (2020a). Statistical Database: All valid permits by reason, length of validity and citizenship on 31 December of each year. Accessed 17/02/2020.

Eurostat (2020b). Statistical Database: Acquisition of citizenship by age group, sex and former citizenship. Accessed 17/02/2020.

Fratsea, L.-M. and Papadopoulos, A.G. (2020), The social and spatial mobility strategies of migrants: Romanian migrants in rural Greece. In J.F. Rye and O'Reilly (Eds.) International Labour Migration to Europe's Rural Regions (pp. 37-51). Routledge, London.

Glick Schiller, N. and Salazar, N. B. (2013). Regimes of Mobility Across the Globe. Journal of Ethnic and Migration Studies, 39(2), 183-200.

Hannam, K., Sheller, M. and Urry, J. (2006). Editorial: Mobilities, Immobilities and Moorings. Mobilities, 1(1), $1-22$.

Kandylis, G. and Maloutas, T. (2012). Here for good: immigrants' residential mobility and social integration in Athens during the late 1990s. In N. Finney and G. Catney (Eds.) Minority Internal Migration in Europe (pp. 195-214). Ashgate, London.

Kasimis, C., Papadopoulos, A.G. and Zografakis, S. (2015). The precarious status of migrant labour in Greece: Evidence from rural areas. In D. della Porta, T. Silvasti, S. Hänninen and M. Siisiäinen (Eds.), The New Social Division: Making and Unmaking Precariousness (pp. 101-119). Palgrave Macmillan, London.

Kesselring, S. (2006). Pioneering mobilities: new patterns of movement and motility in a mobile world. Environmental and Planning A, 38(2), 269-279.

Ketsetzopoulou, M. (2017). Income distribution and living standard in crisis-stricken Greece. In N. Demertzis, D. Balourdos, I. Kikilias, N. Spyropoulou and M. Chrysakis (Eds.) The Social Portrait of Greece 2016-2017 (pp. 359-373). ION, Athens (in Greek).

King, R. (2000). Southern Europe in the changing global map of migration. In R. King, G. Lazaridis, and C. Tsardanidis (Eds.) Eldorado or Fortress? Migration in Southern Europe (pp. 3-26). Palgrave Macmillan, London.

Knights, M. and King, R. (1998). The geography of Bangladeshi migration to Rome. International Journal of Population Geography, 4(4), 299-321.

Koser, K. (2010). Dimensions and dynamics of irregular migration. Population, Space and Place, 16(3), 181-193.

Mitrakos, T. (2018). Economic inequalities, poverty and social exclusion: international experience and the case of Greece in the recent crisis. Social Policy, 9, 7-24.

Munck, R. (2013). The precariat: a view from the south. Third World Quarterly, 34, 747-762.

OECD (2016). OECD Economic Surveys: Greece 2016. Paris: OECD Publishing.

Papadopoulos, A.G. (2011). Migration and security threats in south-eastern Europe. Southeast European and Black Sea Studies, 11(4), 451-469.

Papadopoulos, A.G., Chalkias, C. and Fratsea, L.-M. (2013). Challenges to immigrant associations and NGOs in contemporary Greece. Migration Letters, $10(3), 342$.

Papadopoulos, A.G. and Fratsea, L.-M. (2015). Delineating the geographical mobility of African immigrants towards Greece: Between transnationalism and integration. In G. Seker, A. Tilbe, M. Okmen, P. Yazgan Hepgul, D. Eroglu, I. Sirkeci (Eds.) Turkish Migration Conference 2015. Selected Proceedings (pp. 276-283). Transnational Press London.

Papadopoulos, A.G. and Fratsea, L.-M. (2017). Migrant labour and intensive agricultural production in Greece: the case of the Manolada strawberry industry. In A. Corrado, C. do Castro and D. Perrota (Eds.) Migration and Agriculture (pp. 152-168). Routledge. 
Papadopoulos, A.G., Fratsea, L.-M. and Mavrommatis, G. (2018). Governing migrant labour in an intensive agricultural area in Greece: Precarity, political mobilization and migrant agency in the fields of Manolada. Journal of Rural Studies, 64, 200-209.

Paret, M., (2016). Towards a precarity agenda. Global Labour Journal, 7 (2), 111-122.

Paret, M. and Gleeson, S. (2016). Precarity and agency through a migration lens. Citizenship Studies, 20 (3/4), 277-294.

Priori, A. (2017). Bangladeshi Multi-Scalar Im/mobilities: Between Social Aspirations and Legal Obstacles. New Diversities, 19(3), ISSN-Internet 2199-8116.

Salazar, N. B. (2011). The Power of Imagination in Transnational Mobilities. Identities, 18(6), 576-598.

Sheller, M. and Urry, J. (2006). The new mobilities paradigm. Environment and Planning A, 38(2), 207-226.

Shukaitis, S. (2013). Recomposing precarity: notes on the laboured politics of class composition. Ephemera theory politics in organization, 13 (3), 641-658.

Sorkar, M.N.I. (2020). COVID-19 Pandemic Profoundly Affects Bangladeshi Workers Abroad with Consequences for Origin Communities. Migration Information Source (available from https://www.migrationpolicy.org/article/covid-19-pandemic-profoundly-affects-bangladeshi-workersabroad-consequences-origin).

Standing, G. (2011). The Precariat: The New Dangerous Class. Bloomsbury Academic, London.

Valenzuela Jr, A. (2001). Day labourers as entrepreneurs? Journal of Ethnic and Migration Studies, 27(2), 335 352.

Van Hear, N. (2014). Reconsidering Migration and Class. International Migration Review, 48, S100-S121. 